\title{
COP 21 et éducation | Compte-rendu
}

4 décembre 2015

Francis Thubé

\section{CpenEdition}

Journals

Édition électronique

URL : https://journals.openedition.org/ere/1839

DOI : 10.4000/ere.1839

ISSN : 2561-2271

Éditeur

Centr'ERE

Édition imprimée

Date de publication : 1 septembre 2016

ISSN : 1373-9689

\section{Référence électronique}

Francis Thubé, «COP 21 et éducation | Compte-rendu », Éducation relative à l'environnement [En ligne], Volume 13 - 1 | 2016, mis en ligne le 15 septembre 2016, consulté le 21 septembre 2021. URL : http:// journals.openedition.org/ere/1839; DOI : https://doi.org/10.4000/ere.1839

Ce document a été généré automatiquement le 21 septembre 2021.

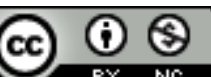

La revue Éducation relative à l'environnement est mise à disposition selon les termes de la Licence Creative Commons Attribution - Pas d'Utilisation Commerciale 4.0 International. 


\section{COP 21 et éducation | Compte-rendu}

\section{4 décembre 2015}

\section{Francis Thubé}

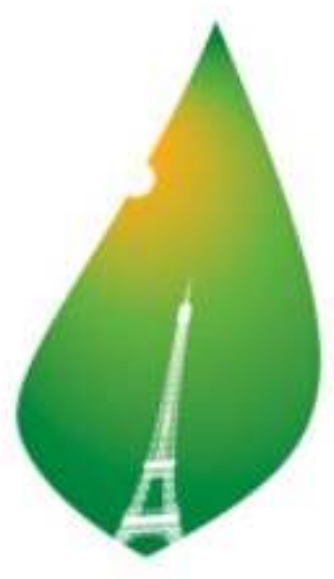

\section{PARIS2015 \\ UN CLIMATE CHANGE CONFERENCE COP21·CMP11}

1 Il s'est tenu en France la 21e Conférence des parties à la Convention-cadre des Nations unies sur les changements climatiques (COP21/CMP11), du 30 novembre au 11 décembre 2015. Étape finale d'un long processus de négociation, cette Conférence est considérée comme une échéance cruciale ayant abouti à un nouvel accord international sur le climat, applicable à tous, pour maintenir le réchauffement climatique en dessous de $2^{\circ} \mathrm{C}$.

2 Pour parvenir à ce nouvel accord universel sur le climat, les délégués des 195 paysparties à la Convention-cadre des Nations unies sur les changements climatiques (CCNUCC) s'étaient régulièrement réunis en 2015 pour avancer sur le texte qui a été voté à Paris le 12 décembre.

Lors de la première session de négociations, du 8 au 13 février à Genève (Suisse), ils ont mené des travaux à partir des premiers éléments déjà produits lors de la COP20 de Lima (Pérou), du 1er au 14 décembre 2014. Au terme d'une semaine de travail, les délégués se sont mis d'accord sur un texte de 86 pages qui a servi de base pour les sessions 
suivantes, au nombre de quatre. La dernière session a eu lieu du 19 au 23 octobre à Bonn (Allemagne), siège de la CCNUCC. Les 1300 délégués ont finalisé le texte qui a été discuté lors de la COP21.

4 Appréciée par le plus grand nombre comme étant une réussite en termes de construction et de mise en accord des parties prenantes (19,385 délégués nationaux), cette COP21 est la première qui a donné la parole aux acteurs de l'éducation en parallèle des négociations.

5 Le 4 décembre 2015 s'est en effet tenue une journée thématique sur l'éducation. La ministre française de l'Éducation nationale et de l'Enseignement supérieur, Najat Vallaud-Belkacem, a mis à l'honneur l'éducation à l'environnement et au développement durable (EEDD) au cœur de la «Conférence Paris Climat» (COP 21), en présence de ses homologues des autres pays, de la ministre française de l'Écologie, Ségolène Royal, de la Directrice générale de l'Unesco, Irina Bokova, ainsi que des ONG qui œuvrent sur le terrain tels que le Réseau École et nature et l'Institut de formation et de recherche en éducation à l'environnement (Ifrée).

6 "Cette initiative du gouvernement français sur le thème de l'Éducation représente une évolution majeure dans l'histoire des COP », a fait valoir Mme Vallaud-Belkacem. La ministre a réuni également ses homologues marocain (Rachid Belmokhtar, qui accueillera la COP 22 en novembre 2016) et gabonais (Florentin Moussavou). Ce dernier est également vice- président de la conférence des ministres de l'Éducation des États et gouvernements de la francophonie (CONFEMEN) et représente à ce titre, 44 ministres de l'Éducation.

7 Les ministres se sont engagés à promouvoir l'EEDD au sein de leur pays et ont invité « l'ensemble des ministres de l'Éducation à travers le monde à se saisir de ces enjeux, et notamment de l'enjeu du réchauffement climatique ». Cette invitation trouve un relais de poids dans la Convention des parties elle- même, à plusieurs endroits du document.

8 Inscrites dans le chapitre relatif au renforcement des capacités, l'éducation, la formation et la sensibilisation sont encouragées par la Conférence des parties : l'article 83 «engage toutes les Parties à veiller à ce que l'éducation, la formation et la sensibilisation du public prévues à l'article 6 de la Convention et à l'article $12 \mathrm{de}$ l'Accord soient bien prises en compte dans leur contribution au renforcement des capacités ».

9 De même, en annexe de la Convention des parties, l'Accord de Paris affirme ceci dans son article 12 : «Les Parties coopèrent en prenant, selon qu'il convient, des mesures pour améliorer l'éducation, la formation, la sensibilisation, la participation du public et l'accès de la population à l'information dans le domaine des changements climatiques, compte tenu de l'importance que revêtent de telles mesures pour renforcer l'action engagée au titre du présent Accord. »

10 Convention-cadre et accord de Paris: http://unfccc.int/resource/docs/2015/cop21/ fre/logf.pdf 


\section{AUTEUR}

\section{FRANCIS THUBÉ}

Institut de formation et de recherche en éducation à l'environnement - Ifrée 